\title{
Simple Measurement of Carbon Films on Copper Tubes and Their Effects on Corrosion
}

\author{
Takashi Iyasu', Motoki Kuratani², Itaru Ikeda3 ${ }^{3}$, Noriyuki Tanaka3 ${ }^{3}$ Yutaka Yamada,4, \\ Osamu Sakurada ${ }^{2}$ \\ ${ }^{1}$ Technical Support Department, Kurita Water Industries Ltd., Tochigi, Japan \\ ${ }^{2}$ Gifu University, Gifu, Japan \\ ${ }^{3}$ Technical Research Laboratory, DAI-DAN Co., Ltd., Saitama, Japan \\ ${ }^{4}$ Daiwa Techno Co., Ltd., Gifu, Japan \\ Email: t.iyasu78@kurita-water.com,z4524032@edu.gifu-u.ac.jp, ikedaitaru@daidan.co.jp, tanakanoriyuki@daidan.co.jp, \\ y_yamada@gifu-u.ac.jp, sakurada@gifu-u.ac.jp
}

How to cite this paper: Iyasu, T., Kuratani, M., Ikeda, I., Tanaka, N., Yamada, Y. and Sakurada, O. (2021) Simple Measurement of Carbon Films on Copper Tubes and Their Effects on Corrosion. Open Journal of Composite Materials, 11, 12-22. https://doi.org/10.4236/ojcm.2021.111002

Received: November 12, 2020

Accepted: January 9, 2021

Published: January 12, 2021

Copyright $\odot 2021$ by author(s) and Scientific Research Publishing Inc. This work is licensed under the Creative Commons Attribution International License (CC BY 4.0).

http://creativecommons.org/licenses/by/4.0/

(c) (i) Open Access

\begin{abstract}
It has been reported that pitting corrosion in copper tubes occurs due to the effect of a carbon film produced by the influence of undergoing an oil and heat treatment. As a quantitative method for determining the residual carbon amount, it has been reported that the inner surface of a copper tube can be dissolved with a mixed acid to collect and analyze the adhering carbon; however, this method is dangerous and difficult. Therefore, two methods were examined as a simple quantitative method for obtaining the residual carbon amount using copper tubes with known residual carbon amounts. One method utilizes X-ray photoelectron spectroscopy (XPS), and the other method utilizes the potential difference between the carbon film-adhered surface and carbon film-removed surface. In regard to XPS measurement, a linear correlation was found between the spectral intensity of $\mathrm{C}$ and the residual carbon amount; therefore, XPS measurements were considered to be effective as a simple measurement method for the carbon film on the inner surface of a copper tube. In the evaluation method by measuring the corrosion potential, a correlation was observed between the potential difference $\Delta \mathrm{E}$ and the residual carbon amount of the inner surface of the tube and the outer surface of the polished tube. It is considered possible to estimate the residual carbon amount from the prepared calibration curve. Through these studies, it is suggested that the carbon film was non-uniformly present on the surface of the copper tube. Therefore, the galvanic current was measured, and the effect of a non-uniform carbon film on corrosion behavior was investigated. As a result, in the measurement of galvanic current, the current flowed from the copper tube with a large amount of residual carbon (cathode) to the copper tube with
\end{abstract}


a small amount of residual carbon (anode). In addition, the higher the area ratio of the carbon film was, the larger the galvanic current tended to be.

\section{Keywords}

Copper Tube, Residual Carbon, Pitting Corrosion, Cooling Water System, Refrigerator, XPS

\section{Introduction}

Since copper has high thermal conductivity and is easy to process, it is widely used in the heat exchangers of air conditioning equipment and in sanitary equipment. Additionally, copper is known as a corrosion-resistant material in fresh water [1]; however, it has been reported that type I pitting corrosion is caused by the synergistic effect between the water quality and the carbon film produced by the influence of undergoing an oil and heat treatment [2] [3] [4]. It has also been reported that the occurrence of pitting corrosion is suppressed even in the presence of a carbon film by adding a water treatment agent to the cooling water [5] [6]. In regard to a quantitative method to analyses this carbon film, it has been reported that after degreasing the inside of the tube with an organic solvent, the inside surface of the tube is dissolved with a mixture of nitric and hydrochloric acid to collect and analyze the attached carbon [7]. However, this method is dangerous because it uses a mixed acid. Additionally, since the amount of the carbon film adhered to the inner surface of the tube (hereinafter referred to as "residual carbon amount") is small; many copper tubes are required for quantification. Since this analysis can be dangerous and difficult, a safe and simple method for measuring the carbon film as the residual carbon amount is desired.

Therefore, in this study, two methods were examined as a simple quantitative method for the residual carbon amount through the use of copper tubes with a known residual carbon amount. One is a method that utilizes X-ray photoelectron spectroscopy (XPS), and the other is a method that uses the potential difference between the carbon film-adhered surface and the carbon film-removed surface. In addition, through these studies, it was suggested that the carbon film was non-uniformly present on the surface of the copper tube; thus, the galvanic current was measured and the effect of a non-uniform carbon film on corrosion behavior was investigated.

\section{Method}

\subsection{Test Materials}

JIS H3300 C1220 phosphorus-deoxidized soft copper tubes with 9 different levels of residual carbon amount were used as the test material. Table 1 shows the residual carbon amount of these test materials, along with the tube dimensions for the corresponding tests. The test material with a residual carbon amount of 
Table 1. Description of the test materials.

\begin{tabular}{cccccccccc}
\hline $\begin{array}{c}\text { Residual Carbon } \\
\text { Amount }\left[\mathrm{mg} / \mathrm{m}^{2}\right]\end{array}$ & 0 & 0.5 & 1.0 & 2.1 & 5.3 & 6.1 & 6.6 & 13.0 & 23.0 \\
\hline Diameter $\varphi[\mathrm{mm}]$ & 15.2 & 15.2 & 15.9 & 15.9 & 15.9 & 15.9 & 15.9 & 15.9 & 15.9 \\
Thickness t $[\mathrm{mm}]$ & 0.4 & 0.4 & 0.8 & 0.8 & 0.8 & 0.8 & 0.8 & 0.8 & 0.8 \\
Test I & - & - & - & $\bullet$ & - & - & $\bullet$ & $\bullet$ & $\bullet$ \\
Test II & - & - & - & - & - & - & - & $\bullet$ & - \\
Test III & - & - & - & - & - & - & - & - & $\bullet$ \\
\hline
\end{tabular}

$0 \mathrm{mg} / \mathrm{m}^{2}$ was prepared by immersing $0.5 \mathrm{mg} / \mathrm{m}^{2}$ test material in 3.0 mass\% sulfuric acid for $10 \mathrm{~s}$ and then thoroughly rinsing with water. In a test that evaluated the relationship between the peak intensity of $\mathrm{C}$ and the residual carbon amount using XPS (hereinafter referred to as "Test I"), a copper tube was cut in half, opened like a plate, and then washed with acetone for $10 \mathrm{~s}$. In the test in which the relationship between the corrosion potential difference between the carbon film-adhered surface (inner surface of the tube) and the carbon filmremoved surface (outer surface of the tube) was measured to determine the residual carbon amount (hereinafter referred to as "Test II"), the length of the test material was $50 \mathrm{~mm}$. The inner surface of the tube was only degreased with acetone, and the outer surface of the tube was polished 5 times with 400\# emery polishing paper in the axial direction of the tube and then degreased with acetone. In addition, after coating the cut surface of the tube end, one of the tube ends was closed with a silicon plug and used for the test. In a test in which the correlation between the carbon film and corrosion was investigated by measuring the galvanic current while short-circuiting the test materials with residual carbon amounts of 0 and $23.0 \mathrm{mg} / \mathrm{m}^{2}$ and different area ratios (hereinafter referred to as "Test III"), the test material was halved and degreased with acetone; then, the other parts were coated so that the exposed inner surface of the tube was 1,2 and $4 \mathrm{~cm}^{2}$.

\subsection{Test Equipment}

A Quantera SXM instrument (ULVAC-PHI) was used for the XPS measurement in Test I. Figure 1 shows the measurement points with a residual carbon amount of $6.6 \mathrm{mg} / \mathrm{m}^{2}$ as an example. Moreover, the plate-shaped test material was fixed to a holder with carbon tape, as shown in Figure 1, and there were 10 measurement points with $3 \mathrm{~mm}$ intervals on each test material. The photoelectron spectra of $\mathrm{C} 1 \mathrm{~s}, \mathrm{Cu} 2 \mathrm{p}_{3 / 2}$, and O1s were measured at a pass energy of $55.0 \mathrm{eV}$ using an $\mathrm{Al} \mathrm{Ka}$ radiation source $(\mathrm{h} \nu=1486.6 \mathrm{eV})$ with a beam diameter of $100 \mu \mathrm{m}$, an acceleration voltage of $15 \mathrm{kV}$, and an output of $25 \mathrm{~W}$. The calibration of the binding energy of each data point was performed with the $\mathrm{C} 1 \mathrm{~s}$ peak at 285.0 $\mathrm{eV}$. 


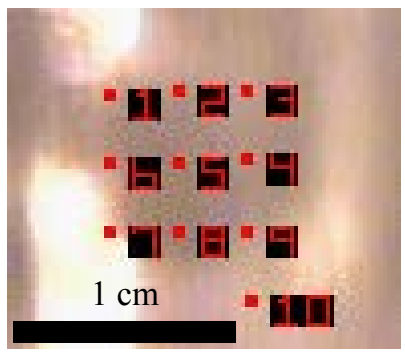

Figure 1. Schematic showing the measurement points for XPS.

Figure 2 shows a schematic diagram of the test equipment for Test II. The test water used was a $\mathrm{pH} 6$ aqueous solution in which $\mathrm{KCl}$ was dissolved in pure water; the $\mathrm{KCl}$ concentrations were adjusted to $0.1,0.5,1.0,2.0$ and $3.3 \mathrm{M}$. The test material was placed in a $100 \mathrm{~mL}$ beaker, and $80 \mathrm{~mL}$ of test water was poured into the beaker to measure the corrosion potential on the outer surface of the tube. Then, $4 \mathrm{~mL}$ of test water was poured into the tube to measure the corrosion potential on the inner surface of the tube. A potentiostat (Hokuto Denko: HZ-5000) was used to measure the corrosion potential, and an $\mathrm{Ag} / \mathrm{AgCl}$ electrode was used as the reference electrode. The measurement time was set to $150 \mathrm{~s}$, and the potential was measured at $\mathrm{n}=5$.

Figure 3 shows a schematic diagram of the test equipment for Test III. A 0.5 $\mathrm{M} \mathrm{KCl}$ aqueous solution was used as the test water, and the test was conducted at room temperature under open-air conditions and stirred at $300 \mathrm{rpm}$. Briefly, $200 \mathrm{~mL}$ of test water was placed in a $200 \mathrm{~mL}$ beaker. The area ratio was adjusted to residual carbon amounts of 0 and $23.0 \mathrm{mg} / \mathrm{m}^{2}$ test specimens; additionally, a distance of approximately $2 \mathrm{~cm}$ was set between the electrodes, and a non-resistance ammeter (Hokuto Denko HM-103A) was used. The current was measured at $\mathrm{n}=3$. The current density was calculated by converting the measured current value per unit area.

\section{Results and Discussion}

\subsection{Test I Evaluation by XPS Analysis}

Figure 4 shows the XPS spectra of $\mathrm{C} 1 \mathrm{~s}, \mathrm{Cu} 2 \mathrm{p}_{3 / 2}$, and $\mathrm{O} 1 \mathrm{~s}$ at residual carbon amounts of $0,6.6$, and $23.0 \mathrm{mg} / \mathrm{m}^{2}$. The $\mathrm{C} 1 \mathrm{~s}$ peak tended to increase as the residual carbon amount increased. At a residual carbon amount of $23.0 \mathrm{mg} / \mathrm{m}^{2}$, a shoulder was recognized at approximately $286 \mathrm{eV}$. It is thought that this was due to the carbon film. On the other hand, in the spectrum of $\mathrm{Cu} 2 \mathrm{p}_{3 / 2}$, the peak tended to decrease as the residual carbon amount increased, and it is thought that the exposed area of copper decreased due to the carbon film. The $\mathrm{O}$ 1s peak also tended to decrease as the residual carbon amount increased.

Figure 5 shows the average and standard deviation of the integrated intensities of the $\mathrm{C} 1 \mathrm{~s}$ and $\mathrm{Cu} 2 \mathrm{p}_{3 / 2}$ peaks for each residual carbon amount at 10 measurement positions. It was observed that the integrated intensity of the $C$ s peak increased linearly with the residual carbon amount and that $\mathrm{Cu} 2 \mathrm{p}_{3 / 2}$ decreased 


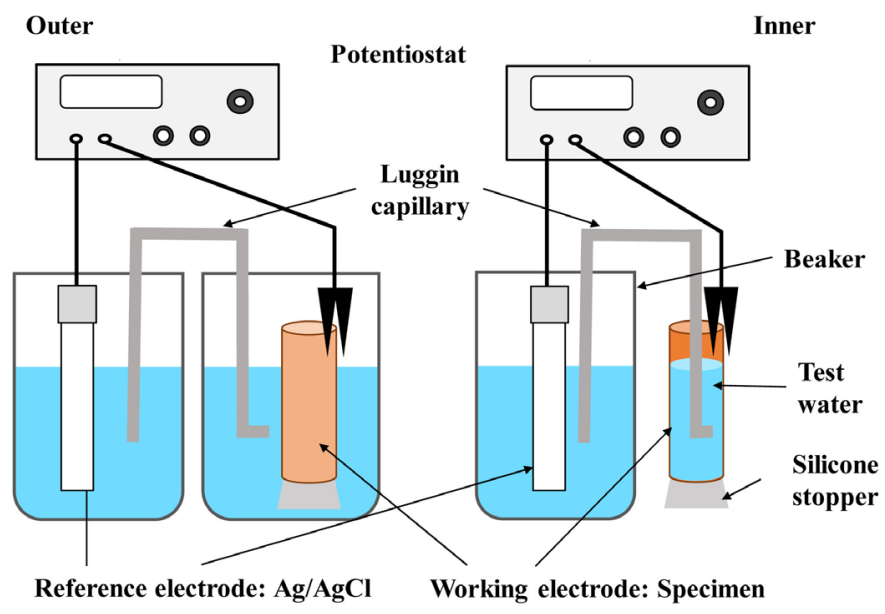

Figure 2. Schematic diagram showing the corrosion potential measurement device.

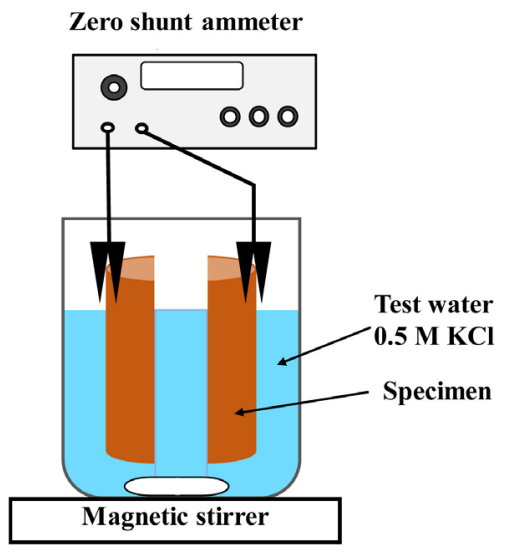

Figure 3. Schematic diagram the experimental galvanic current measurement.
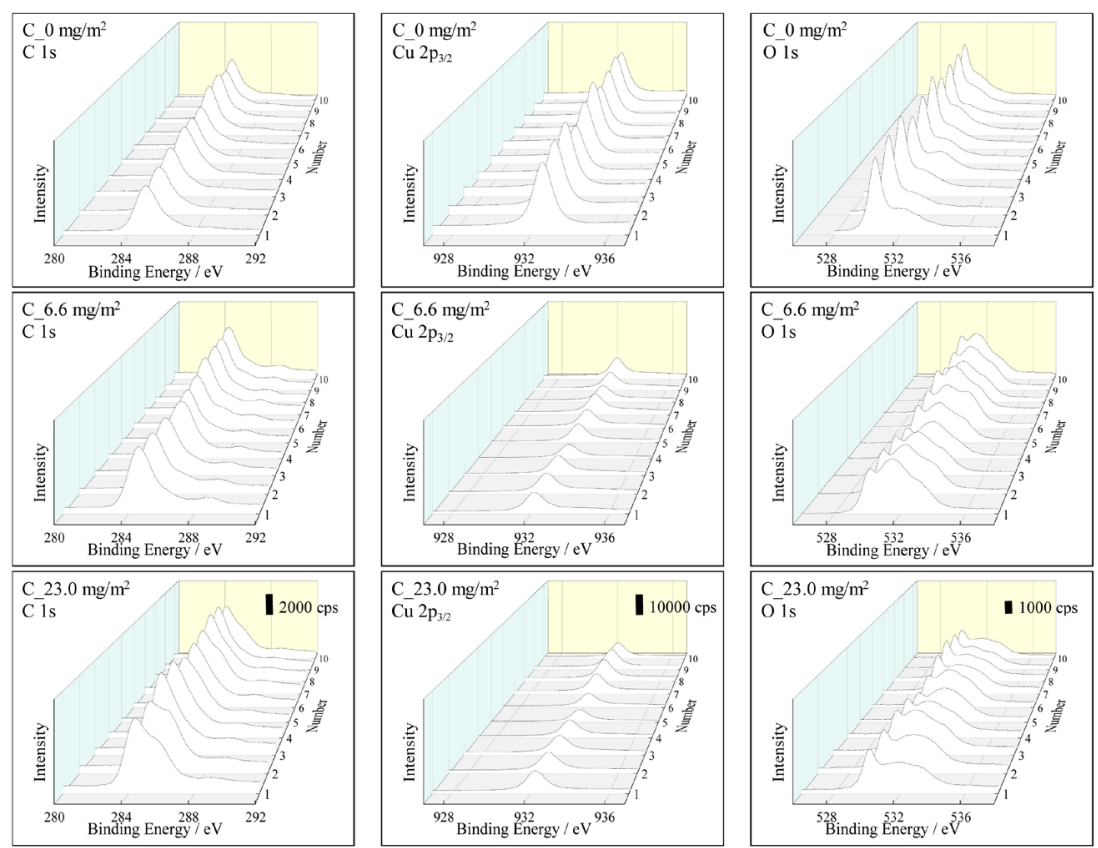

Figure 4. XPS measurement results (residual carbon amount 0, 6.6 and $23.0 \mathrm{mg} / \mathrm{m}^{2}$ ). 

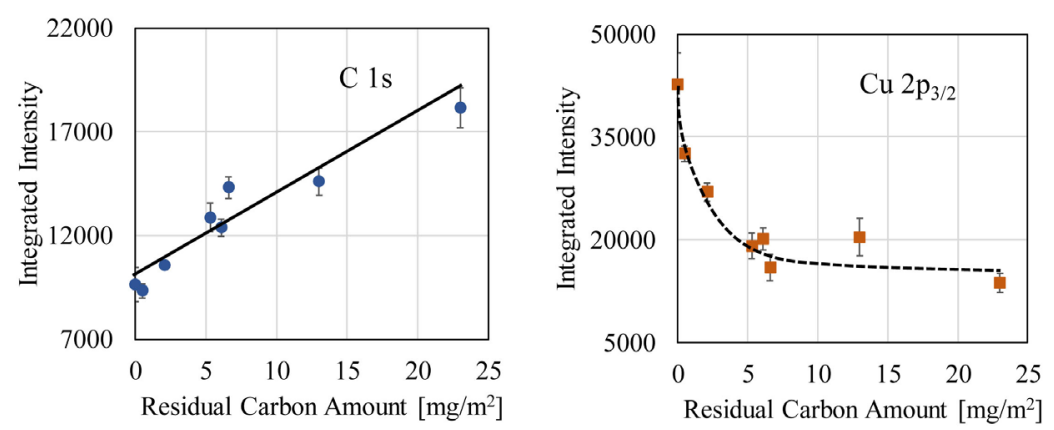

Figure 5. Relationship between the residual carbon amount and integrated intensity of $\mathrm{C}$ $1 \mathrm{~s}$ and $\mathrm{Cu} 2 \mathrm{p}_{3 / 2}$. Error bars indicate the SD $(\mathrm{n}=10)$.

exponentially. Since the residual carbon amount and the integrated intensity of the peak at $\mathrm{C} 1 \mathrm{~s}$ showed a linear response, it is considered possible to quantify the residual carbon amount on the inner surface of the tube by measuring the $\mathrm{C}$ 1 s peak by XPS.

Based on the above results, it is considered that XPS measurements were effective as a simple quantitative method for measuring the residual carbon amount. However, as a more versatile quantification method, an evaluation method by potential measurements was examined.

\subsection{Test II Evaluation by Potential Difference}

\subsubsection{Corrosion Potential Measurement}

Figure 6 shows an example of the corrosion potential measurement results on the inner and outer surfaces of the test material with a residual carbon amount of $6.6 \mathrm{mg} / \mathrm{m}^{2}$ in $0.5 \mathrm{M} \mathrm{KCl}$. The corrosion potential on the outer surface was almost constant immediately after immersion approximately $-0.18 \mathrm{~V}$ vs. $\mathrm{Ag} / \mathrm{AgCl}$, and the corrosion potential on the inner surface was $-0.08 \mathrm{~V}$ vs. $\mathrm{Ag} / \mathrm{AgCl} \mathrm{im}-$ mediately after immersion, and then gradually decreased with time. Similar tendencies were observed in test water with other $\mathrm{KCl}$ concentrations. The gradual decrease in the inner surface potential was considered to be due to the carbon film. Hereafter, the values after $30 \mathrm{~s}$ of immersion were used in this report.

\subsubsection{Examination of the $\mathrm{KCl}$ Concentration and Internal Observation Results}

Figure 7 shows the relationship between the residual carbon amount and the potential difference $\Delta \mathrm{E} 30 \mathrm{~s}$ after the start of immersion at each $\mathrm{KCl}$ concentration. In comparison with $0.5 \mathrm{M} \mathrm{KCl}$, which showed a linear correlation between the residual carbon amount and $\Delta \mathrm{E}, \Delta \mathrm{E}$ showed a large value from 0.07 to $0.09 \mathrm{~V}$ vs. $\mathrm{Ag} / \mathrm{AgCl}$ with $0.1 \mathrm{M} \mathrm{KCl}$, and no correlation was observed. On the other hand, with $1.0 \mathrm{M} \mathrm{KCl}$ or higher, the $\Delta \mathrm{E}$ of $1.0 \mathrm{M} \mathrm{KCl}$ showed a large value that was similar to that with $0.5 \mathrm{M} \mathrm{KCl}$ at a residual carbon amount of $1.0 \mathrm{mg} / \mathrm{m}^{2}$. In contrast, $\Delta \mathrm{E}$ values of 2.0 and $3.3 \mathrm{M} \mathrm{KCl}$ were similar, showing small values of approximately 0.02 to $0.04 \mathrm{~V}$ vs. $\mathrm{Ag} / \mathrm{AgCl}$, regardless of the residual carbon amount. No clear correlation was found between the residual carbon amount and $\Delta \mathrm{E}$ 


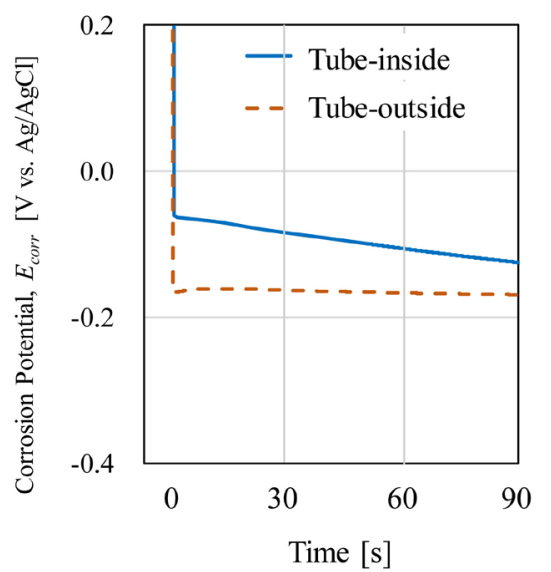

Figure 6. Potential measurement results $(0.5 \mathrm{M} \mathrm{KCl}$ test solution, residual carbon amount 6.6 $\left.\mathrm{mg} / \mathrm{m}^{2}\right)$.

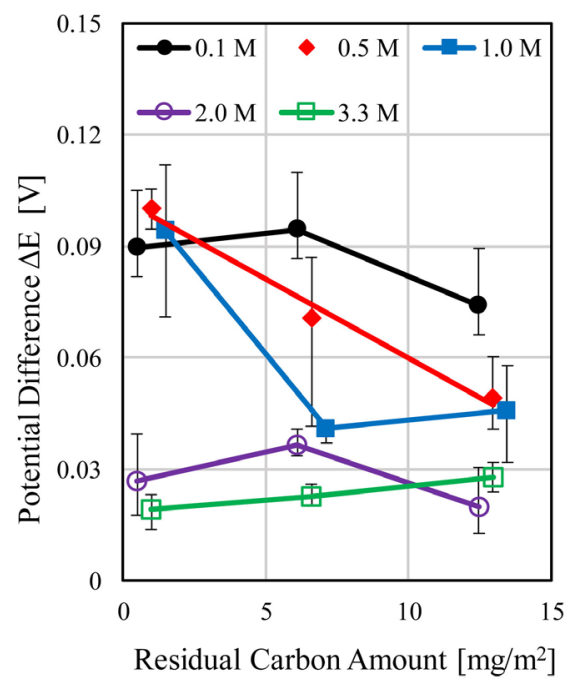

Figure 7. Relationship between the residual carbon amount with several concentrations of $\mathrm{KCl}$ and the potential difference $30 \mathrm{~s}$ after the start of immersion.

with $1.0 \mathrm{M} \mathrm{KCl}$ or higher. The reason why $\Delta \mathrm{E}$ became small with high $\mathrm{KCl}$ concentrations is that in this test, copper ions were concentrated near the surface over time because there was no flow velocity under static conditions; thus, it is considered that the higher the $\mathrm{KCl}$ concentration is, the faster the elution and concentration of the copper ions.

Figure 8 shows the observation results of the inner surface after the test with a solution of $2.0 \mathrm{M} \mathrm{KCl}$ as an example. At $1.0 \mathrm{mg} / \mathrm{m}^{2}$ of residual carbon, the entire inner surface was reddish brown, at $6.6 \mathrm{mg} / \mathrm{m}^{2}$ of residual carbon, a mixed reddish brown surface with metallic luster was observed, and at $13.0 \mathrm{mg} / \mathrm{m}^{2}$ of residual carbon, most of the inner surface had a metallic luster. The reddish brown was considered to be a copper oxide, and the metallic luster was considered to be a carbon film. Therefore, it was presumed that when the residual carbon amount was approximately $6.0 \mathrm{mg} / \mathrm{m}^{2}$, the presence or absence of the carbon film varied widely, and the carbon film adhered unevenly. 


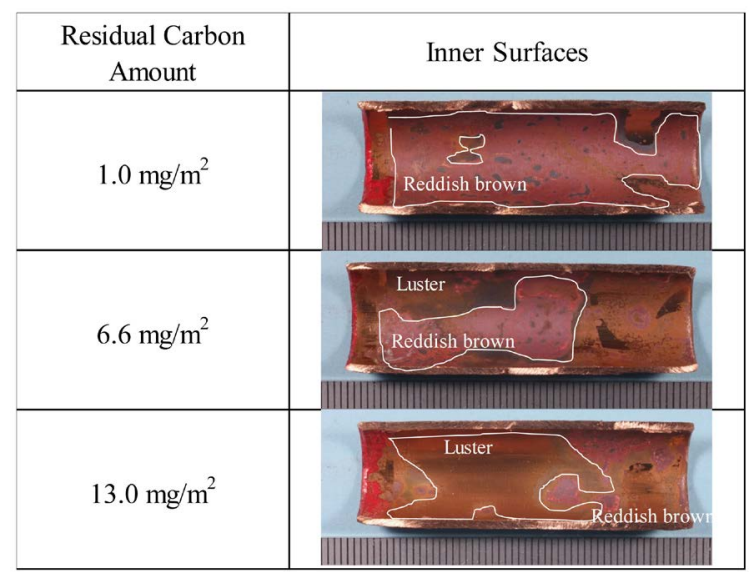

Figure 8. Observations of the inner surfaces (2.0 M KCl test solution).

From the above results, the relationship between the residual carbon amount and $\Delta \mathrm{E}$ was linear after $30 \mathrm{~s}$ from the start of immersion in the $0.5 \mathrm{M} \mathrm{KCl}$ solution at $\mathrm{pH}$ 6. Therefore, it was judged that this condition was suitable for obtaining a calibration curve for evaluating the amount of carbon film adhered to the inner surface of the copper tube.

\subsubsection{Verification by Market Products}

Figure 9 shows the approximate formula of the residual carbon amount and $\Delta \mathrm{E}$ obtained by adding the result of the residual carbon amount of $6.1 \mathrm{mg} / \mathrm{m}^{2}$ to the previous results ( $\mathrm{pH} 6,0.5 \mathrm{M} \mathrm{KCl}$ and $30 \mathrm{~s}$ after the start of immersion), and the measurement results of the market products (commercially available products and actual heat transfer tube for refrigerators). In the approximate formula, it was confirmed that the error of $\Delta \mathrm{E}$ was larger than the others when the residual carbon amount was approximately $6.0 \mathrm{mg} / \mathrm{m}^{2}$. The inner surface observation results in Figure 8 were considered to be due to the uneven adhesion of the carbon film. In the verification of market products, the commercial product (b) with a residual carbon amount $23.0 \mathrm{mg} / \mathrm{m}^{2}$ and the actual heat transfer tube with a residual carbon amount of $5.0 \mathrm{mg} / \mathrm{m}^{2}$ generally followed a linear approximation. The commercial product (a) with a residual carbon amount of $9.7 \mathrm{mg} / \mathrm{m}^{2}$ exhibited a value that deviated from the linear approximation, but it was considered to be within the variation range of industrial products. Since the standard deviation of $\Delta \mathrm{E}$ was large for copper tubes with a residual carbon amount of approximately $6.0 \mathrm{mg} / \mathrm{m}^{2}$, we would like to improve the accuracy of the approximation by increasing the number of samples in the future.

\subsection{Test III Galvanic Current Measurement}

Figure 10 shows the changes over time in the measured values of the galvanic current at each area ratio. The galvanic current flowed so that the test specimen with a residual carbon amount of $0 \mathrm{mg} / \mathrm{m}^{2}$ became the anode and the test specimen with $23.0 \mathrm{mg} / \mathrm{m}^{2}$ became the cathode, which was the same as previous reports [8] [9]. The current density was stable $30 \mathrm{~s}$ from the start of measurement 


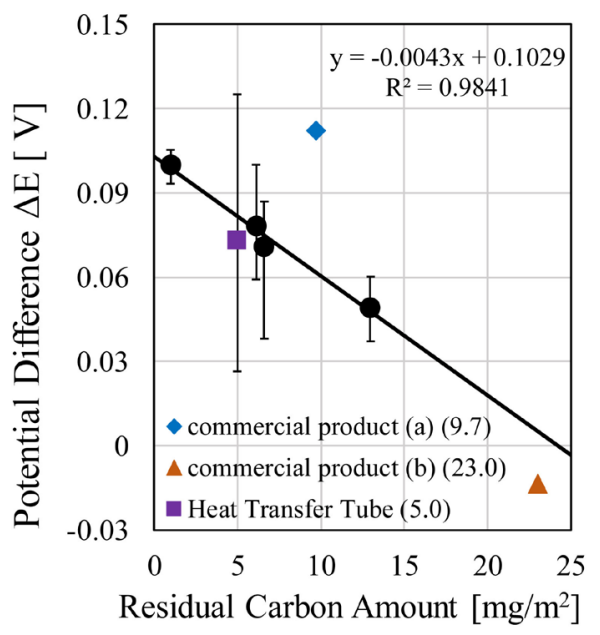

Figure 9. Verification results with actual tubes and heat transfer tubes.



Figure 10. Galvanic current measurement results at several area ratios.

regardless of the area ratio. In addition, the larger the area ratio with $23.0 \mathrm{mg} / \mathrm{m}^{2}$ residual carbon is, that is, the larger the area ratio of the carbon film, the higher the current density tended to be.

The area ratios 4:1, 2:1, 1:1, 1:2 and 1:4 were represented by the carbon film occupancy, and the relationships between the carbon film occupancy and the current density immediately after the start of measurement, after $30 \mathrm{~s}$ and after $180 \mathrm{~s}$ are shown in Figure 11. Immediately after the start of the measurement, the current density increased sharply from approximately $33 \%$ of carbon film occupancy to approximately $66 \%$, this behavior was almost constant regardless of the carbon film occupancy. After 30 and $180 \mathrm{~s}$, the current density increased linearly with increasing carbon film occupancy, and after approximately $66 \%$, it tended to increase more rapidly. The relationship between the carbon film occupancy and the current density shown in Figure 11 suggested that the carbon film occupancy was significantly related to corrosion. It was also considered that the higher the carbon film occupancy is, the larger the galvanic current flowing 


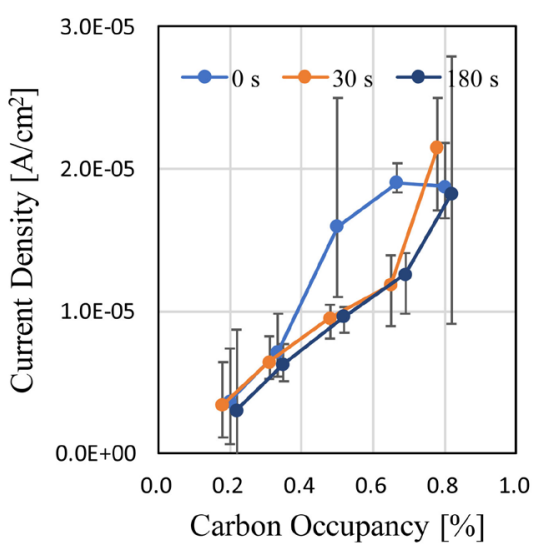

Figure 11. Relationship between the carbon occupancy and current density.

through the local new surface of copper, which makes pitting corrosion more likely to occur.

\section{Conclusions}

As a simple quantitative analysis of the residual carbon amount, we examined the surface by an XPS analysis and by evaluating the corrosion potential measurement using a copper tube with a known residual carbon amount. We also investigated the effect of a non-uniform carbon film on the copper tube surface on the corrosion behavior and obtained the following results.

1) In the XPS measurements, the spectral intensity of $C 1 \mathrm{~s}$ tended to increase, and the spectral intensity of $\mathrm{Cu} 2 \mathrm{p}$ tended to decrease as the residual carbon amount increased.

2) In regard to the $C 1 \mathrm{~s}$ spectra, a linear correlation was found between the spectral intensity and the residual carbon amount; thus, the XPS analysis was considered to be effective as a simple measurement method for the carbon film on the inner surface of the copper tube. It is considered that the residual carbon amount could be estimated from the calibration curve by XPS analysis.

3) In the evaluation method by measuring the corrosion potential, a correlation was observed between the potential difference $\Delta \mathrm{E}$ and the residual carbon amount of the inner surface (with a carbon film) of the tube and the outer surface (without a carbon film) of the polished tube $30 \mathrm{~s}$ after the start of immersion at room temperature and using $0.5 \mathrm{M} \mathrm{KCl}$ at a $\mathrm{pH}$ of 6 . Therefore, it is considered possible to estimate the residual carbon amount from the prepared calibration curve.

4) When the average residual carbon amount was approximately $6.0 \mathrm{mg} / \mathrm{m}^{2}$, the error range was considered to be wide due to the non-uniformity of the carbon film.

5) In the measurement of galvanic current, it was found that the higher the carbon film occupancy is, the larger the galvanic current tended to be.

6) It is considered that the higher the carbon film occupancy is, the larger the galvanic current on the local new surface and the more likely it is that pitting 
corrosion will occur.

7) In the future, we would like to increase the number of samples and improve the accuracy of the XPS measurement and corrosion potential measurement methods.

\section{Acknowledgements}

This research was partially supported by a 2019 research grant from the Japan Institute of Copper. We are grateful to Dr. H. Tamagawa (UACJ Copper Co., Toyokawa-shi, Aichi Prefecture, Japan) who provided specimens for the test. In addition, we are grateful to Mr. K. Kawano (UACJ Co., Chiyoda-ku, Tokyo, Japan) for cooperation with the experiments.

\section{Conflicts of Interest}

The authors declare no conflicts of interest regarding the publication of this paper.

\section{References}

[1] Notoya, T. (2008) Corrosion Resistance and Corrosion of Copper. Rust Prevention \& Control Japan, 1, 25-32.

[2] Cornwall, F.J., Wildsmith, G. and Gilbert, P.T. (1976) Pitting Corrosion in Copper Tubes in Cold Water Service. ASTM STP, 576, 155-179. https://doi.org/10.1520/STP41404S

[3] Yamada, Y., Mizutani, K. and Inoue, Y. (2014) Development of Corrosion Protection Research for Copper Tube over the Last Few Decades and Future Prospects. Zairyo-to-Kankyo, 63, 158-162.

[4] Yamada, Y. (2019) Development of Corrosion Protection Research for Copper Tube in Recent Years and Future Prospects. Refrigeration, 94, 73-77.

[5] Iyasu, T., Toyokawa, K., Kuratani, M., Ikeda, I., Tanaka, N., Yamada, Y. and Sakurada, O. (2020) Field Evaluation of New Water Treatment Chemical against Type I" Pitting Corrosion of Copper Tube. Journal of Japan Institute of Copper, 59, 115-119.

[6] Iyasu, T., Kuratani, M., Ikeda, I., Tanaka, N., Yamada, Y. and Sakurada, O. (2020) A Study of Water Treatment Chemical Effects on Type I" Pitting Corrosion of Copper Tubes. Materials Sciences and Applications, 11, 494-504. https://doi.org/10.4236/msa.2020.117034

[7] Yamada, Y., Mori, A., Hatanaka, R., Atsumi T. and Nakao, N. (1998) Pitting Corrosion of Copper Coiled Tubes in the Air Conditioning System Having the Open Heat Storage Water Tank. Zairyo-to-Kankyo, 47, 723-728. https://doi.org/10.3323/jcorr1991.47.723

[8] Sakai, M., Seri, O., Yamada, Y., Toda, I. and Iitsuka, M. (2002) Effect of Residual Carbon Deposits on Corrosion Behavior of Copper Tube Filled with Water. Zairyoto-Kankyo, 51, 12-16. https://doi.org/10.3323/jcorr1991.51.12

[9] Yamanaka, H., Nagai, T., Nonaka, H., Tsuchiya, H. and Fujimoto, S. (2020) Effect of Deposits on Corrosion of Copper Tubes in a Circulating Cooling Water System. Zairyo-to-Kankyo, 69, 17-25. https://doi.org/10.3323/jcorr.69.17 